\title{
Resolution-Dependent Estimates of Multiple Sclerosis Lesion Loads
}

\author{
M.K. Erskine, L.L. Cook, K.E. Riddle, J.R. Mitchell, S.J. Karlik
}

\begin{abstract}
Background: Changes in brain lesion loads assessed with magnetic resonance imaging obtained at 1.5 Telsa (T) are used as a measure of disease evolution in natural history studies and treatment trials of multiple sclerosis. Methods: A comparison was made between the total lesion volume and individual lesions observed on 1.5 $\mathrm{T}$ images and on high-resolution $4 \mathrm{~T}$ images. Lesions were quantified using a computer-assisted segmentation tool. Results: There was a $46 \%$ increase in the total number of lesions detected with $4 \mathrm{~T}$ versus $1.5 \mathrm{~T}$ imaging $(\mathrm{p}<0.005)$. The $4 \mathrm{~T}$ also showed a $60 \%$ increase in total lesion volume when compared with the $1.5 \mathrm{~T}(\mathrm{p}<0.005)$. In several instances, the $1.5 \mathrm{~T}$ scans showed individual lesions that coalesced into larger areas of abnormality in the $4 \mathrm{~T}$ scans. The relationship between individual lesion volumes was linear (slope 1.231) showing that the lesion volume observed at $4 \mathrm{~T}$ increased with the size of the lesion detected at $1.5 \mathrm{~T}$. The $4 \mathrm{~T}$ voxels were less than one quarter the size of those used at $1.5 \mathrm{~T}$ and there were no consistent differences between their signal-to-noise ratios. Conclusions: The increase in signal strength that accompanied the increase in field strength compensated for the loss in signal amplitude produced by the use of smaller voxels. This enabled the acquisition of images with improved resolution, resulting in increased lesion detection at $4 \mathrm{~T}$ and larger lesion volumes.
\end{abstract}

RÉSUMÉ: Estimation du fardeau lésionnel par l'imagerie en fonction de la résolution dans la sclérose en plaques. Introduction: Les changements du fardeau lésionnel cérébral évalués par imagerie par résonance magnétique obtenue à 1,5 Telsa (T) sont utilisés comme mesure de l'évolution de la maladie dans les études sur l'histoire naturelle de la maladie et au cours des essais thérapeutiques dans la sclérose en plaques. Méthodes: Le volume total des lésions et les lésions individuelles observées sur des images 1,5 T ont été comparés aux données obtenues sur des images $4 \mathrm{~T}$ à haute résolution. Un outil de segmentation assistée par ordinateur a été utilisé pour quantifier les lésions. Résultat: L'imagerie $4 \mathrm{~T}$ détectait $46 \%$ plus de lésions que l'imagerie $1,5 \mathrm{~T}(\mathrm{p}<0,005)$ et un volume total de lésions $60 \%$ plus élevé $(\mathrm{p}<0,005)$. Dans plusieurs cas, les scans $1,5 \mathrm{~T}$ montraient des lésions individuelles qui se fusionnaient en zones anormales plus vastes sur les scans $4 \mathrm{~T}$. La relation entre le volume individuel des lésions était linéaire (pente de 1,231) démontrant que le volume des lésions observées sur l'imagerie $4 \mathrm{~T}$ augmentait selon la taille de la lésion détectée à l'imagerie 1,5 T. Les voxels $4 \mathrm{~T}$ étaient moins que le quart de la taille de ceux utilisés à 1,5 T et il n'y avait pas de différence constante entre leur rapport signal-bruit. Conclusions: L'augmentation de la force du signal qui accompagnait l'augmentation de la force du champ magnétique compensait pour la perte d'amplitude du signal produit par l'utilisation de voxels plus petits, ce qui permettait l'acquisition d'images dont la résolution était meilleure et donc une meilleure détection des lésions et une meilleure appréciation de leur volume par l'imagerie 4 T.

Can. J. Neurol. Sci. 2005; 32: 205-212

Multiple sclerosis (MS) is a chronic debilitating disease of the central nervous system (CNS) characterized by multifocal demyelinated areas throughout the white matter. ${ }^{1}$ During the course of MS, the integrity of the blood brain barrier is compromised, inflammatory cells enter the CNS and demyelination ensues. It is hypothesized that in genetically susceptible individuals, an autoimmune response against myelin antigens is initiated by exposure to an environmental factor. ${ }^{1-3}$ The severity of clinical symptoms is more often related to the location of the damage than to the degree and extent of the pathological process. ${ }^{4}$ The disease course, both within and between subjects, is highly variable. ${ }^{2}$

Magnetic resonance imaging (MRI) provides an objective and direct assessment of the evolving pathology in MS.
Inflammation and demyelination produce increased water content in MS lesions, making them relatively easy to discern from other neuroanatomical structures. ${ }^{5}$ As MRI technology advances, it is likely that MR techniques will continue to play an important role in investigating the natural history of the disease

From the Departments of Physiology, (MKE, LLC, SJK); Pathology (SJK); University of Western Ontario; Diagnostic Radiology and Nuclear Medicine (KER, SJK); London Health Sciences Centre, London, Ontario; Calgary Neuroscience Research Group (JRM); University of Calgary, Calgary, Alberta, Canada

ReCEIVED NOVEMber 18, 2003. ACCEPTED IN FINAL FORM November 8, 2004. Reprint requests to: Stephen J Karlik, University of Western Ontario, 1151 Richmond Street, Department of Pathology, Dental Science Building 4035, London, Ontario N6A 5C1 
and monitoring treatment efficacy. ${ }^{6}$ MRI systems that exceed 3 Tesla $(\mathrm{T})$ are able to produce higher resolution images within a similar time frame to conventional clinical systems $(1.5 \mathrm{~T})$. The higher resolution images may be more accurate in detecting MS lesions, which could result in earlier diagnosis of clinically definite MS, a better understanding of the underlying pathological process of the disease and more precise monitoring of treatment effects. While the potential benefits of higher field MRI systems include higher signal-to-noise ratio (SNR), high speed of acquisition, increased resolution, and the capability for MR spectroscopy and functional imaging, there is a definite cost advantage to employing middle-field-strength units. Although there is a consensus that magnets with higher field strengths produce images that are subjectively better than lower field systems, this has not been proven to result in increased accuracy in the detection of pathology. 7,8

The objective of this research was to determine if the number of lesions, lesion volume, and total lesion load detected within the MS brain would be different on images acquired at $4 \mathrm{~T}$ versus 1.5 T. It was hypothesized that high resolution $4 \mathrm{~T}$ MRI images would result in an increased detectable lesion load when compared with standard clinical MRI exams performed at $1.5 \mathrm{~T}$.

\section{MethodS}

\section{Subjects}

Written informed consent was obtained with the approval of the University of Western Ontario's Review Board for Health Sciences Research Involving Human Subjects. Eight outpatients with clinically definite secondary progressive MS were recruited from the London Health Sciences Centre Multiple Sclerosis Clinic, Ontario, Canada. The subjects mean age was 42.8 years; mean duration of disease was 9.1 years; with an average Expanded Disability Status Scale score of 4.0. The eight subjects underwent $4 \mathrm{~T}$ MR imaging just prior to, or immediately following a regularly scheduled $1.5 \mathrm{~T}$ imaging. In some cases the two examinations occurred on separate days, however, the $4 \mathrm{~T}$ exams were always completed within 48 hours of imaging at 1.5 $\mathrm{T}$.

\section{MR Imaging}

1.5 Tesla imaging was performed with a transmit-receive quadrature head RF coil on GE Signa ${ }^{\mathrm{TM}}$ scanners (GE Medical Systems, Milwaukee, WI) by technicians in the department of diagnostic radiology and nuclear medicine, University CampusLondon Health Sciences Centre, either as part of the subjects' ongoing care or as part of a concomitant, through unrelated, clinical trial. Axial images through the brain were obtained in the oblique plane with the corpus callosum as an internal landmark, with slices angled along the inferior aspect of the genu and splenium of the corpus callosum. The exam consisted of the acquisition of T2-weighted (T2W) and proton density weighted images using a dual echo spin echo sequence and T1-weighted (T1W) conventional spin echo sequence. The $4 \mathrm{~T}$ imaging was performed using a custom-made $27 \mathrm{~cm}$ diameter quadrature birdcage RF head coil on a ${ }^{\text {UNITY INOVA }}{ }^{\mathrm{TM}}$ MR scanner (Varian Associates, Palo Alto, CA and Siemens Medical Systems, Erlangen, Germany) with the axial images acquired in a -similar manner to the $1.5 \mathrm{~T}$ imaging. A three-dimensional magnetization-prepared fast low-angle shot (mpFLASH3d) sequence was used to obtain the T1W images at $4 \mathrm{~T}$ and conventional spin echo sequence was used for the T2W images. ${ }^{9}$ The T2W sequence parameters of the two field strengths (2000 $\mathrm{ms}$ at $1.5 \mathrm{~T}$ and $4000 \mathrm{~ms}$ at $4 \mathrm{~T}$ ) were selected from previous in vivo research of the guinea pig brain obtained from the same scanners. ${ }^{5}$ Imaging parameters are summarized in the Table.

\section{Imaging Techniques and Analysis}

All 1.5 $\mathrm{T}$ and $4 \mathrm{~T}$ images were digitized and transferred to a Sun SPARC 4 workstation (Sun Microsystems, Mountain View, CA) for processing. Three-dimensional image sets were created from each exam by stacking the $\mathrm{T} 1 \mathrm{~W}$ and $\mathrm{T} 2 \mathrm{~W}$ (or proton density weighted and T2W) images, respectively. ${ }^{10}$ Since a greater number of $\mathrm{T} 1 \mathrm{~W}$ images were acquired compared to the $\mathrm{T} 2 \mathrm{~W}$ images at $4 \mathrm{~T}$, the excess $\mathrm{T} 1 \mathrm{~W}$ slices were not included in the 3D image sets. The $1.5 \mathrm{~T}$ and $4 \mathrm{~T}$ image sets were then analysed with the aid of the computer-assisted, semi-automated image segmentation program, Segtool, employing an algorithm based on multispectral analysis and $k$-nearest-neighbour clustering. ${ }^{10}$ This method used a computer to outline lesions from an operator selected starting point, followed by manual editing. The program employed an algorithm based on multispectral analysis that provided interactive assistance to a knowledgeable operator and acted locally upon individual lesions. A $k$-nearest-neighbour cluster classification was applied

Table: Summary of Imaging Parameters

\begin{tabular}{|c|c|c|}
\hline Parameters & $1.5 \mathrm{~T}$ & $4 \mathrm{~T}$ \\
\hline MR scanner & $\begin{array}{l}\text { GE Signa LX MR } \\
\text { scanner }\end{array}$ & $\begin{array}{l}{ }^{\mathrm{UNITY}} \text { INOVA } \\
\text { scanner }\end{array}$ \\
\hline \multirow[t]{3}{*}{ T2-/PD-weighted } & $\begin{array}{l}\text { Dual echo spin } \\
\text { echo pulse }\end{array}$ & $\begin{array}{l}\text { Conventional spin } \\
\text { echo }\end{array}$ \\
\hline & TR $2000 \mathrm{~ms}$ & TR $4000 \mathrm{~ms}$ \\
\hline & TE $30 / 80 \mathrm{~ms}$ & TE $70 \mathrm{~ms}$ \\
\hline \multirow[t]{4}{*}{ T1-weighted } & $\begin{array}{l}\text { Conventional spin } \\
\text { echo }\end{array}$ & mpFLASH3d \\
\hline & TR $550 \mathrm{~ms}$ & TR $11.8 \mathrm{~ms}$ \\
\hline & TE $13 \mathrm{~ms}$ & TE $6 \mathrm{~ms}$ \\
\hline & & $11^{\circ}$ flip angle \\
\hline Number of Slices & 30 & $\begin{array}{l}\text { T2-/PD-weighted } 39 \\
\text { T1-weighted } 64\end{array}$ \\
\hline Slice thickness & Contiguous $5 \mathrm{~mm}$ & Contiguous $2.2 \mathrm{~mm}$ \\
\hline Field of View (FOV) & $22 \mathrm{~cm} \times 16 \mathrm{~cm}$ & $22 \mathrm{~cm} \mathrm{x} 22 \mathrm{~cm}$ \\
\hline Matrix & $256 \times 192$ & $512 \times 256$ \\
\hline Number of excitations & T2-/PD-weighted 1 & $\begin{array}{l}\text { T2-/PD-weighted } 2 \\
\text { (average) }\end{array}$ \\
\hline$(\mathrm{NEX})$ & T1-weighted 2 (average) & T1-weighted 1 \\
\hline Voxel & $3.58 \mathrm{~mm}^{3}$ & $0.812 \mathrm{~mm}^{3}$ \\
\hline Duration of scan & $\begin{array}{l}\text { T2-/PD-weighted } \\
11 \text { min } \\
\text { T1-weighted } 6 \text { min } \\
\text { Total } 17 \text { min }\end{array}$ & $\begin{array}{l}\text { T2-/PD-weighted } \\
34 \text { min } \\
\text { T1-weighted } 5 \text { min } \\
\text { Total } 39 \text { min }\end{array}$ \\
\hline
\end{tabular}

$\mathrm{TR}=$ repetition time; $\mathrm{TE}=$ echo 
to differentiate the intensity characteristics of a single lesion from that of surrounding tissue. The lesion voxels were then identified by the computer and edited. ${ }^{10}$ A lesion was outlined when it appeared on both the $\mathrm{T} 1 \mathrm{~W}$ and $\mathrm{T} 2 \mathrm{~W}$ images on the image set. The SNRs of the lesions, white matter, gray matter and cerebrospinal fluid (CSF) of each MR contrast were calculated at both field strengths by dividing mean signal intensity of the tissue by the standard deviation of the air. Contrast-to-noise ratios (CNRs) were also calculated between white matter and lesion, grey matter and lesion, and CSF and lesion by taking the difference the signal intensity difference between the two tissues (e.g. white matter and lesion) and dividing it by the standard deviation of air.

Once the initial lesions were identified on both sets of images from each patient, a lesion-to-lesion comparison began. Images acquired at $4 \mathrm{~T}$ and $1.5 \mathrm{~T}$ were displayed simultaneously on the computer monitor and lesions that appeared on both image sets were identified. The 3D connected-component labeling feature of Segtool made it possible to identify a lesion that extended through multiple slices. The volume of each lesion was calculated by multiplying the lesion area by the slice thickness. Therefore, from each image set, the number and volume of individual lesion volumes were recorded and total lesion load (summation of all lesion volumes throughout the brain) was calculated.

Due to the obvious differences in the in-plane and out-ofplane resolution of the images, the operator was not blinded to the field strength used to acquire the images. Thus, to ensure minimal intra-observer variability, the $1.5 \mathrm{~T}$ and $4 \mathrm{~T}$ image sets of each patient were analysed at least one week apart and reviewed 24 hours following the completion of the initial identification process. The intra-observer reliability exceeded 94\% throughout the study.

The identification of individual lesions was complicated when focal lesions appeared to merge resulting in areas of confluent abnormality. In such cases it was necessary for the operator to make subjective judgments as to the identification of a lesion as distinct or part of a diffuse abnormality. Only lesions that were identified with certainty by the operator were further analyzed. An expert observer (SJK) further verified the identification and volume from randomly selected image sets. The inter-rater reliability exceeded $95 \%$.

One subject was excluded from the lesion number and volume comparisons due to the diffuse nature of the identified lesions. A second subject was also excluded in the analysis of lesion volume due to a small difference in the imaging plane at 4 $\mathrm{T}$ versus $1.5 \mathrm{~T}$. These factors (diffuse lesions and angle incompatibility) made the positive identification and accurate quantification of the corresponding lesions difficult and unreliable.

\section{Statistical Analysis}

Product-moment correlation analysis was used to investigate the relationship between the number of lesions detected, the total lesion load, and the individual lesion volumes. A one-way analysis of variance was employed to examine differences between image SNR and CNR. Post hoc comparisons were performed using Dunnett's test. In all cases, a 95\% confidence limit was used to determine significance.

\section{RESULTS}

\section{Signal-to-Noise and Contrast-to-Noise Ratios}

There was a higher mean CSF and lesion SNR on T1W images acquired at $1.5 \mathrm{~T}$ compared to $\mathrm{T} 1 \mathrm{~W}$ images at $4 \mathrm{~T}(\mathrm{p}<$ 0.05 ). No significant differences were found between the mean SNR of white matter or gray matter on the T1W images obtained at 1.5 and $4 \mathrm{~T}$ (Figure 1). The CNR, however, for white matterlesion and gray matter-lesion were higher on the $\mathrm{T} 1 \mathrm{~W}$ images at $4 \mathrm{~T}$, and the CNR for CSF-lesion was significantly lower on the $\mathrm{T} 1 \mathrm{~W}$ images at $4 \mathrm{~T}$ compared to $1.5 \mathrm{~T}$ images $(\mathrm{p}<0.05)$ (Figure 2 ). The SNRs of white matter, gray matter and lesions on the $\mathrm{T} 2 \mathrm{~W}$ images were all significantly higher at $1.5 \mathrm{~T}$ when compared to $4 \mathrm{~T}(\mathrm{p}<0.05)$ (Figure 3$)$. There were no significant difference between CNRs (white matter and lesion, gray matter and lesion, and CSF and lesion) on the T2W images obtained at $1.5 \mathrm{~T}$ and $4 \mathrm{~T}$ (Figure 4).

\section{Total Lesion Number}

A $46 \%$ increase in the total number of lesions was detected with $4 \mathrm{~T}$ imaging as compared to $1.5 \mathrm{~T}$. This linear relationship (slope $=2.146, \mathrm{r}=0.905, \mathrm{p}<0.005, \mathrm{DF}=6$ ) suggests that the total number of lesions detected with $4 \mathrm{~T}$ imaging tend to increase with the total number of lesions detected at $1.5 \mathrm{~T}$ (Figure 5). Figure 6 depicts the breakdown of the total lesions detected with $4 \mathrm{~T}$ imaging with each subject. The number of lesions not detected at $1.5 \mathrm{~T}$ ranged from $6 \%$ to $62 \%$. Eleven percent of lesions identified at $1.5 \mathrm{~T}$ were not viewed on the corresponding $4 \mathrm{~T}$ images.

\section{Lesion Volume}

Individual lesion volumes were significantly increased with 4 $\mathrm{T}$ imaging when compared to $1.5 \mathrm{~T}$. The relationship between lesion volumes at the two field strengths was linear with a correlation coefficient of $0.943(\mathrm{p}<0.001, \mathrm{DF}=135)$, and a slope of 1.231 (Figure 7). Overall, there was a $60 \%$ increase in the mean lesion volume measured at $4 \mathrm{~T}$. The lesions that were seen only with $4 \mathrm{~T}$ imaging had a mean volume $\pm \mathrm{SE}$ of $0.060 \pm$ $0.010 \mathrm{~cm}^{3}$ (range, $0.004-0.470 \mathrm{~cm}^{3}$ ) (Figure 8). The lesions identified only on $1.5 \mathrm{~T}$ images have a mean volume of $0.075 \pm$ $0.020 \mathrm{~cm}^{3}$ (range, $0.009-0.320 \mathrm{~cm}^{3}$ ). Fourteen percent of the lesions identified on both $4 \mathrm{~T}$ and $1.5 \mathrm{~T}$ image sets had measured volumes that were higher at $1.5 \mathrm{~T}$ than at $4 \mathrm{~T}$.

\section{Total Lesion Load}

There was a $51 \%$ increase in the total lesion load of the MS brains measured using $4 \mathrm{~T}$ imaging compared to $1.5 \mathrm{~T}$ imaging. The relationship between the lesion load measurements was linear with a correlation coefficient of $0.954(\mathrm{p}=0.003, \mathrm{DF}=5)$ and a slope of 1.065 (Figure 9). Each subject had an increased lesion load at $4 \mathrm{~T}$ compared to $1.5 \mathrm{~T}$ that ranged from $28 \%$ to $282 \%$. On average $96 \%$ of the increase in total lesion load as measured at $4 \mathrm{~T}$ came from an increase in the volume of individual lesions compared to $1.5 \mathrm{~T}$. The remaining $4 \%$ increase was attributed to the volume of lesions identified at $4 \mathrm{~T}$ that were not seen at $1.5 \mathrm{~T}$. When analyzed on a subject-by-subject basis, the percent contribution of increased lesion volume to the increase in total lesion load was present in all but one subject (Figure 10a). One subject (S3) had a decreased mean volume of lesions at $4 \mathrm{~T}$ than at $1.5 \mathrm{~T}$ resulting in a negative contribution to 


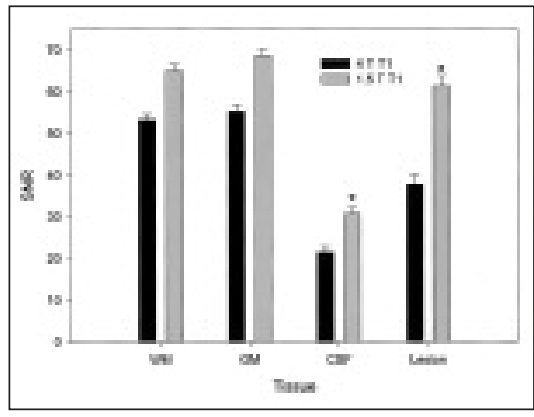

Figure 1: Mean T1W image SNR \pm standard deviation at $1.5 \mathrm{~T}$ and $4 \mathrm{~T}$

No significant differences were found between the mean SNRs of WM (white matter) or GM (gray matter) on the $T 1 W$ images obtained at $1.5 \mathrm{~T}$ and $4 \mathrm{~T}$. However, the greater mean CSF and lesion SNRs on the $1.5 \mathrm{~T} \mathrm{T1W}$ images did reach statistical significance when compared to the $4 T T 1 \mathrm{~W}$ images. ( $*<0.05$, Dunnett's test)

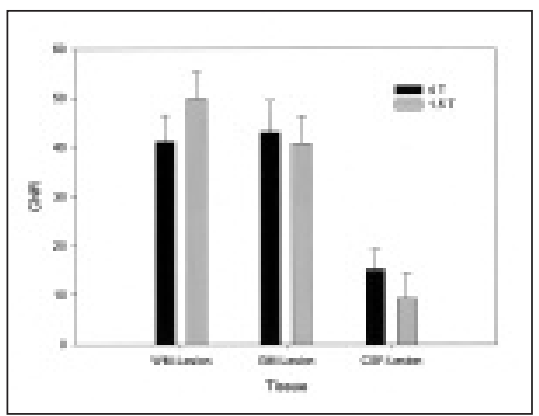

Figure 4: Mean T2W image CNR \pm standard deviation at $1.5 \mathrm{~T}$ and $4 \mathrm{~T}$

No significant differences were found between the CNR for white matter-lesion, gray matter-lesion, and CSF-lesion on T2W images obtained at $4 T$ versus those obtained at $1.5 \mathrm{~T}$.

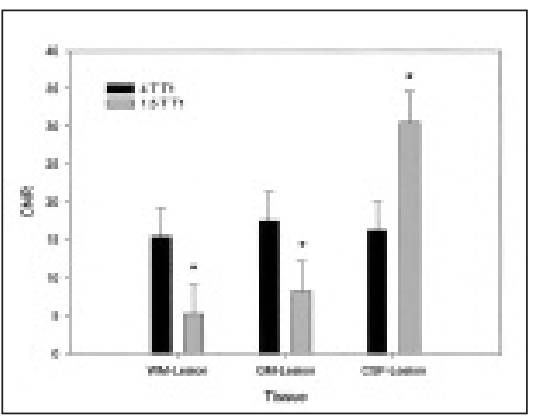

Figure 2: Mean T1W image CNR \pm standard deviation at $1.5 \mathrm{~T}$ and $4 \mathrm{~T}$

The CNR for white matter-lesion and gray matter-lesion was significantly higher on the $4 T T 1 W$ images than on the $1.5 \mathrm{~T}$ images. Conversely, the CSF-lesion CNR was higher on the $1.5 T$ images than it was on the $4 T$ images. (* $p<0.05$, Dunnett's test)

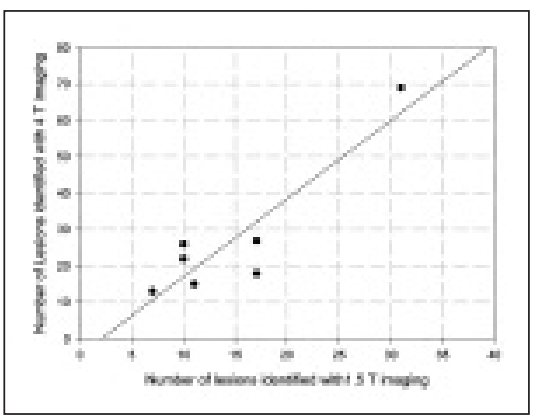

Figure 5: Number of lesions detected using $4 T$ versus $1.5 T$ imaging

The number of lesions detected in each subject, using $1.5 \mathrm{~T}$ imaging, was plotted against the number seen using $4 T$. When all seven subjects were compared there was a $46 \%$ increase in the number of lesions detected using $4 \mathrm{~T}$ versus $1.5 \mathrm{~T}$. As demonstrated by the correlation line, the relationship between individual lesion volumes was linear $(r=0.905, p=0.005$, $D F=6$ ), with a slope of 2.146 showing that the number of lesions detected using $4 T$ imaging increases with the number of lesions detected using lower fields.

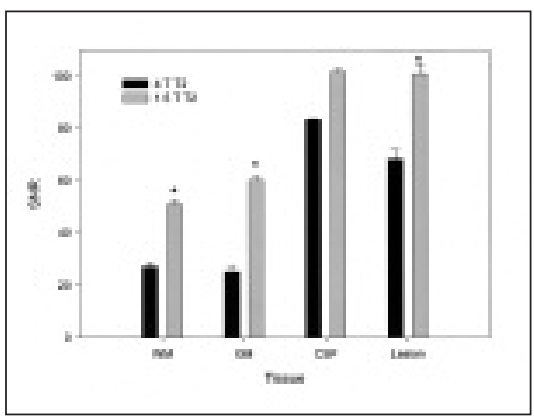

Figure 3: Mean T2W image SNR \pm standard deviation at $1.5 \mathrm{~T}$ and $4 \mathrm{~T}$

No significant difference was found between the mean SNR of CSF on T2W images at 1.5 T and 4 T. T2W 1.5 T images did have larger SNRs for WM (white matter), GM (gray matter), and lesion, which reached statistical significance when compared to the $4 T T 2 W$ images. $(* p<0.05$, Dunnett's test)

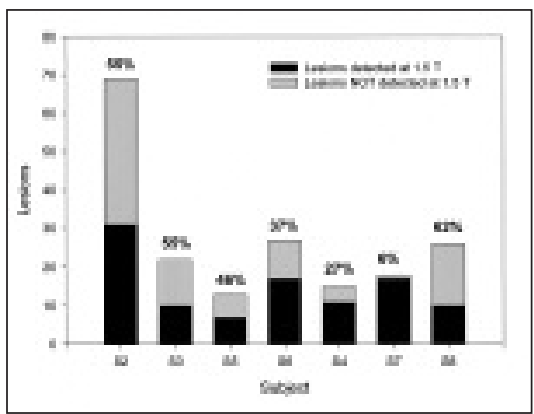

Figure 6: Per subject increase in the number of lesions identified at $4 \mathrm{~T}$

The number of lesions detected at $4 T$ and the percentage of those lesions that were not seen at 1.5 T. The light gray area of each bar represents the number of lesions not detected at $1.5 \mathrm{~T}$, while the lower portions of the bars represent lesion detected at $1.5 \mathrm{~T}$. An increase in the number of lesions identified at $4 \mathrm{~T}$ as compared to $1.5 \mathrm{~T}$ is variably present in all subjects.

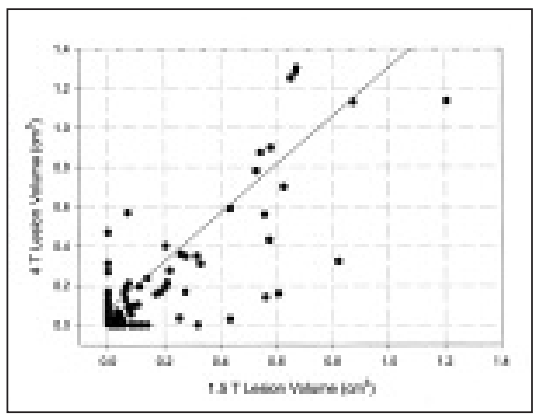

Figure 7: Individual lesion volumes using $4 T$ versus $1.5 T$ imaging.

Individual lesion volumes as measured at $1.5 \mathrm{~T}$ are plotted against volumes measured from a $4 T$ exam. When individual lesions were directly compared $(n=136), 47 \%$ of those seen at $4 T$ were not detected at $1.5 \mathrm{~T}$. These lesions were small with an average mean volume $\pm S E$ of $0.060 \pm 0.010 \mathrm{~cm}^{3}$ (range, $0.004-0.470 \mathrm{~cm}^{3}$ ). As demonstrated by the correlation line, the relationship between individual lesion volumes was linear $(r=0.943(p<0.001, D F=135)$, with a slope of 1.231 showing that the lesion volume detected at $4 \mathrm{~T}$ tend to increase with that detected at lower field. However, $14 \%$ of the lesions measured were larger at $1.5 \mathrm{~T}$ than at $4 \mathrm{~T}$, and $11 \%$ of the lesions seen at $1.5 \mathrm{~T}$ were missed at $4 \mathrm{~T}$. Like their 4 T counterparts, these undetected lesions were small (mean volume $\pm S E$ of $0.075 \pm 0.020 \mathrm{~cm}^{3}$; range, $0.009-0.320 \mathrm{~cm}^{3}$ ). 


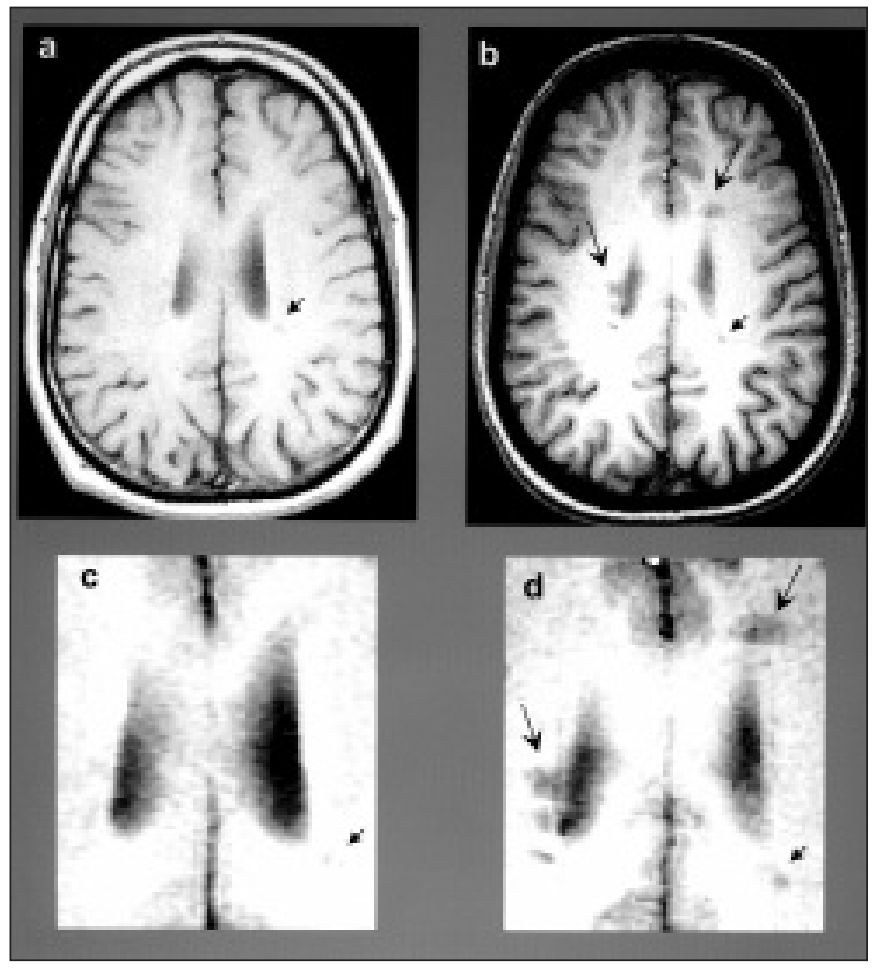

Figure 8: $4 \mathrm{~T}$ Lesions that are not seen at $1.5 \mathrm{~T}$ and a lesion that appears smaller and more focal at $4 \mathrm{~T}$.

T1-weighted images ( $a$ and $b$ ) and enlarged regions of interest ( $c$ and $d$ ) acquired at $1.5 \mathrm{~T}$ (left) and $4 \mathrm{~T}$ (right). These images reveal four lesions that can be identified at $4 \mathrm{~T}$ but not at $1.5 \mathrm{~T}$ (large arrows). Also visible is a lesion that appears smaller and more focal at $4 \mathrm{~T}$ than at $1.5 \mathrm{~T}$. (small arrows).

the increase in $4 \mathrm{~T}$ lesion load (Figure 10b). This negative contribution was offset in subject $\mathrm{S} 3$ by the large positive contribution of volume from lesions identified at $4 \mathrm{~T}$ that were not identified at $1.5 \mathrm{~T}$, producing a net increase in $4 \mathrm{~T}$ lesion load. Figures $10 \mathrm{~b}$ and $\mathrm{c}$ represent subjects who both had lesions identified on the $4 \mathrm{~T}$ images and not at $1.5 \mathrm{~T}$.

\section{DiscuSSION}

This study demonstrated that when compared to standard clinical imaging at $1.5 \mathrm{~T}, 4 \mathrm{~T}$ imaging can detect a greater number of lesions and an increased lesion volume. Within a somewhat longer time frame, higher resolution images can be obtained at $4 \mathrm{~T}$ to detect smaller lesions and increased volume within individual lesions. These two factors ultimately lead to an increased lesion load seen on $4 \mathrm{~T}$ images. The white matter within MS brains viewed during MRI has long been considered to be abnormal and is commonly referred to as "normal appearing" white matter (NAWM). ${ }^{11-13}$ Several studies have examined NAWM and have suggested the "invisible" lesion load would provide a clearer picture as to what is occurring within the MS brain. In the current study, the use of $0.8 \mathrm{~mm}^{3}$ voxel at $4 \mathrm{~T}$ resulted in a $46 \%$ increase in the total number of lesions detected, a $60 \%$ increase in the mean lesion volume measured, and a $51 \%$ increase in total lesion load when compared to the standard $5.3 \mathrm{~mm}^{3}$ voxel size used at $1.5 \mathrm{~T}$ imaging. Volume averaging can cause small lesions or small portions of lesions divided between voxels to go undetected, while the same lesion or part of a lesion located in the middle of a voxel may be easily identified. The increased number of lesions observed in this study was not isolated to a specific anatomical location, but rather was evident throughout the white matter. It would appear that smaller lesions located within the NAWM could be detected with higher resolution images.

Analysis of the increased $4 \mathrm{~T}$ lesion load revealed that $96 \%$ of the increase can be attributed to the larger $4 \mathrm{~T}$ volumes of lesions that were identified at both $4 \mathrm{~T}$ and $1.5 \mathrm{~T}$. The lesions detected on the higher resolution $4 \mathrm{~T}$ images had a more defined lesion edge resulting in a more accurate volume measurement. Only a small fraction (4\%) of the total increase in $4 \mathrm{~T}$ lesion load resulted from the added volume from the newly detected lesions not seen on the lower resolution images. The lesions detected only on the $4 \mathrm{~T}$ images were small in size (mean volume of 0.060 $\pm 0.010 \mathrm{~cm}^{3}$ ). In order to contribute to the lesion load, a large number of these new lesions would have to be present. That is not to say their detection is trivial. The anatomical location of these small lesions may be more beneficial in understanding the functional impairment of the individual or how the disease progresses.

Some of the lesions $(11 \%)$ detected at $1.5 \mathrm{~T}$ were not visible on the $4 \mathrm{~T}$ images. Previous MR studies conducted at $4 \mathrm{~T}$ and 4.7 $\mathrm{T}$ examined the central nervous system of an animal model of MS. ${ }^{14-15}$ Both studies reported an increased signal intensity on T1W images that were associated with lesions that contained edema, inflammation and demyelination. These results suggest that $\mathrm{T} 1 \mathrm{~W}$ images acquired at the higher field strengths have some T2-weighting. Therefore, the contrast on those images may be altered resulting in undetectable lesions.

When the subjects were examined individually, the increase in the number of lesions seen at $4 \mathrm{~T}$ ranged from $6 \%$ to $62 \%$ and the total lesion load ranged from $28 \%$ to $282 \%$. The range seen

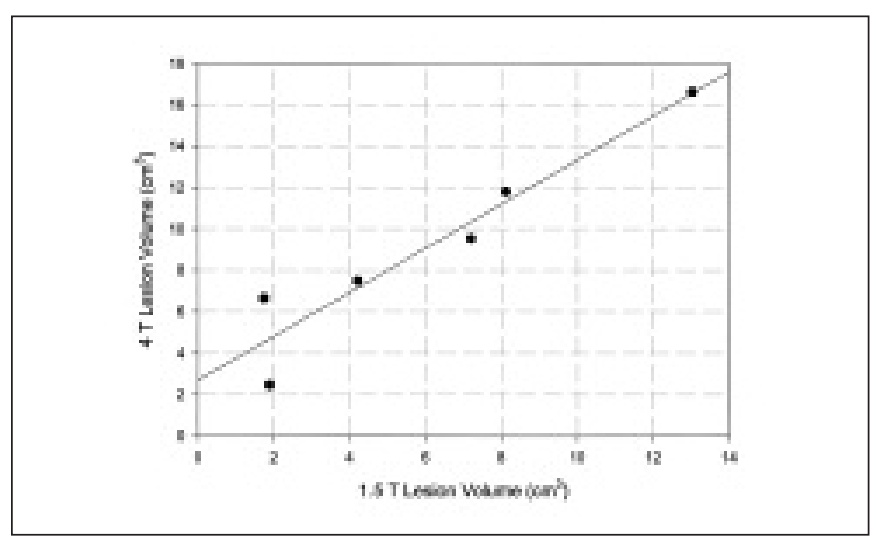

Figure 9: Total lesion load using $4 T$ versus $1.5 T$ imaging

The total lesion load detected in each subject using $1.5 \mathrm{~T}$ imaging is plotted against the total lesion load measured at $4 T$. When all six subjects were compared there was a $51 \%$ increase in the total lesion load detected using $4 \mathrm{~T}$ versus $1.5 \mathrm{~T}$ imaging. As demonstrated by the correlation line, the relationship between the lesion loads was linear $(r=0.954, p=0.003, D F=5)$, with a slope of 1.065, showing that the total lesion load detected at $4 \mathrm{~T}$ tends to increase with increasing $1.5 \mathrm{~T}$ lesion load. 


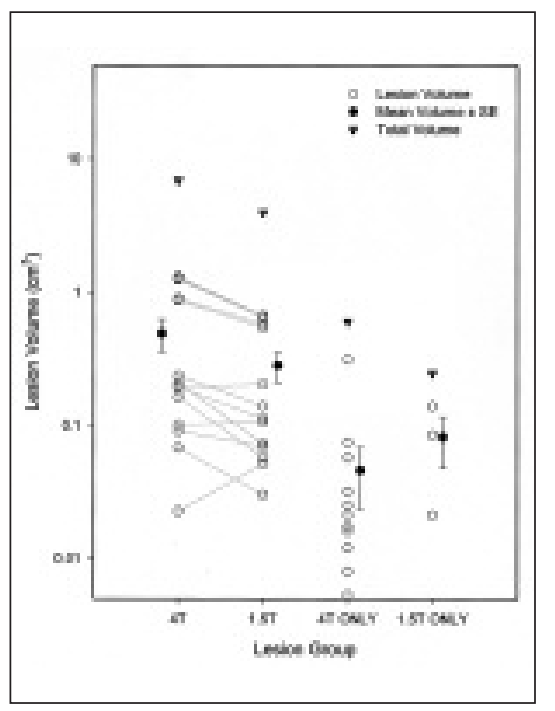

Figure 10a: Individual lesion volumes at $4 T$ and $1.5 \mathrm{~T}$ as measured in subject $\mathrm{S6}$

Comparison of the $4 \mathrm{~T}$ volumes and $1.5 \mathrm{~T}$ volumes of 14 lesions seen at both field strengths in subject S6, as well as of the volumes of the lesions seen only at $4 T$ and the volumes of the lesions seen only at $1.5 \mathrm{~T}$. Although the volume of some individual lesions decreased when measured at $4 T$ as compared to $1.5 \mathrm{~T}$, there was a $74 \%$ increase in both the mean volume $\left(0.492 \pm 0.135 \mathrm{~cm}^{3}\right.$ vs. $\left.0.283 \pm 0.072 \mathrm{~cm}^{3}\right)$ and total volume $\left(6.890 \mathrm{~cm} 3\right.$ vs. $\left.3.961 \mathrm{~cm}^{3}\right)$ of lesions measured at 4 T. A total of 13 lesions, with a mean volume of $0.046 \pm 0.023 \mathrm{~cm}^{3}$ and $a$ total volume of $0.604 \mathrm{~cm}^{3}$, were detected at 4 $T$ and missed at 1.5 T. Three lesions, with a mean volume of $0.082 \pm 0.034 \mathrm{~cm}^{3}$ and $a$ total volume of $0.247 \mathrm{~cm}^{3}$ were not identified at $4 \mathrm{~T}$ and seen only at $1.5 \mathrm{~T}$.

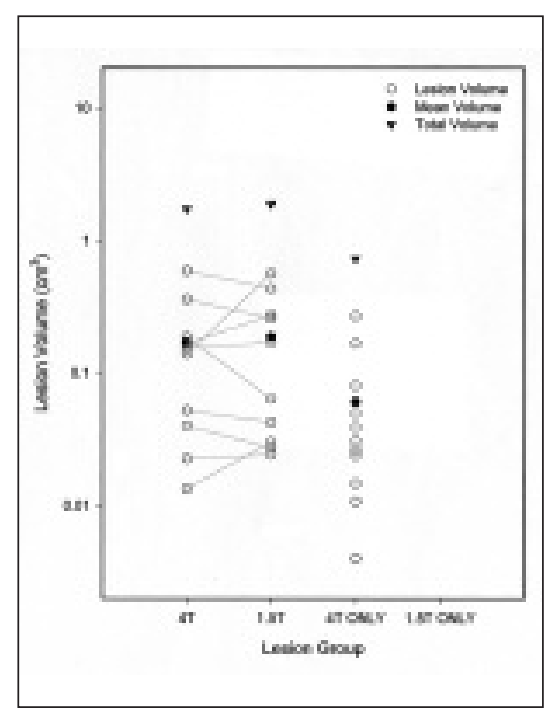

Figure 10b: Individual lesion volumes at $4 T$ and $1.5 \mathrm{~T}$ as measured in subject $\mathrm{S} 3$ Comparison of the $4 \mathrm{~T}$ volumes and $1.5 \mathrm{~T}$ volumes of 10 lesions seen at both field strengths in subject $S 3$, as well as of the volumes of the lesions seen only at $4 T$. There was an $8 \%$ decrease in both the mean volume $\left(0.173 \pm 0.057 \mathrm{~cm}^{3}\right.$ vs. $0.189 \pm 0.060$ $\left.\mathrm{cm}^{3}\right)$ and total volume $\left(1.730 \mathrm{~cm}^{3}\right.$ vs. 1.889 $\mathrm{cm}^{3}$ ) of lesions measured at $4 \mathrm{~T}$ than at $1.5 \mathrm{~T}$, resulting in a negative contribution to the increase in $4 T$ lesion load. This negative contribution was more than offset by the large positive contribution of volume from 12 lesions identified at $4 \mathrm{~T}$ that were not identified at $1.5 \mathrm{~T}$ (Mean volume of $0.061 \pm$ $0.025 \mathrm{~cm}^{3}$ and total volume of $0.729 \mathrm{~cm}^{3}$ ), producing a net increase in 4 T lesion load. No lesions were seen only at $1.5 \mathrm{~T}$.

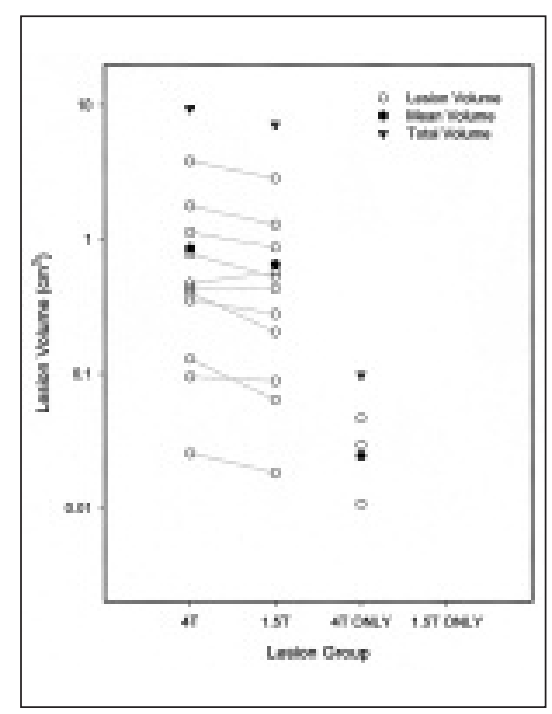

Figure 10c: Individual lesion volumes at $4 T$ and $1.5 \mathrm{~T}$ as measured in subject $\mathrm{S} 4$

Comparison of the $4 \mathrm{~T}$ volumes and $1.5 \mathrm{~T}$ volumes of 11 lesions seen at both field strengths in subject S4, as well as of the volumes of the lesions seen only at $4 T$. Although the volume of some individual lesions decreased when measured at $4 T$ as compared to $1.5 \mathrm{~T}$, there was a $31 \%$ increase in both the mean volume $\left(0.859 \pm 0.337 \mathrm{~cm}^{3}\right.$ vs. $\left.0.654 \pm 0.248 \mathrm{~cm}^{3}\right)$ and total volume $\left(9.447 \mathrm{~cm}^{3}\right.$ vs. $\left.7.193 \mathrm{~cm}^{3}\right)$ of lesions measured at 4 T. A total of 4 lesions, with a mean volume of $0.025 \pm 0.009 \mathrm{~cm}^{3}$ and $a$ total volume of $0.098 \mathrm{~cm}^{3}$, were detected at 4 T and missed at 1.5 T. No lesions were seen only at $1.5 \mathrm{~T}$. in these measurements is not too surprising since the clinical and pathological manifestations of MS are highly variable from one individual to another. All subjects in this study were diagnosed with the secondary-progressive form of MS, but the duration of which the subjects displayed this phenotype ranged from two to 20 years. Biological heterogeneity may the reason for this range in intersubject variability.

When the lesion-to-lesion comparison was analyzed, $14 \%$ of the lesions identified on the $1.5 \mathrm{~T}$ image sets had larger volume measurements than on the $4 \mathrm{~T}$ images. Filippi and colleagues ${ }^{16}$ used an idealized spherical lesion model to investigate the effects of reducing slice thickness on partial volume effects, and noted that lesion volumes tend to be overestimated when lesion dimensions are of the order of the slice thickness. A subject with a large number of convex lesions with dimensions similar to the slice thickness would demonstrate a marked decrease in lesion load. ${ }^{16}$ Thinner slice thickness used to acquire the $4 \mathrm{~T}$ images may have been beneficial in detecting more lesions, but if a lesion's dimension was similar to its slice thickness, the volume of that lesion could have been underestimated.
While quantitative measurement of lesion load in MS is a widely used marker of disease progression, it has been difficult to measure lesion load with a high degree of reproducibility. It has already been shown that several factors markedly influence lesion volume estimates in MS, including intrasubject biological variations, ${ }^{17}$ the use of multiple MR scanners, ${ }^{18,19}$ different pulse sequences, ${ }^{20-24}$ acquisition parameters, ${ }^{16,19,23} \mathrm{~T} 2$ natural lesion oscillation, ${ }^{17}$ segmentation techniques, ${ }^{24-27}$ relatively thin slices, ${ }^{6,19,27-29}$ quality assurance checks, ${ }^{19,27}$ operator training, ${ }^{27,30}$ and accuracy of subject repositioning. ${ }^{19,26,27,31,32}$ Because the magnitude of the variability introduced by all of these factors make it difficult to reliably detect lesion load change, several strategies to reduce the effect of these sources have been developed.,19,27,32-34 Imaging the MS brain at different field strengths in this study dictated the use of different scanners, pulse sequences, and acquisition parameters, thereby contravening many of the strategies developed to reduce the inherent variability of lesion load estimates. Sources of variation in lesion load estimates include the scanners, pulse sequences, subjects, techniques, and operators used in the study. These 
factors influence the quality (i.e. SNR, contrast and spatial resolution) of the resultant images and the results of quantification. Accurate repositioning was complicated by the deficiencies in the $4 \mathrm{~T}$ planning tools despite following the repositioning technique recommended by the ad hoc European Community Committee. ${ }^{34}$

Improvements in image SNR, arising from the use of 3D acquisition, increased voxel size or MR sequences can make a lesion more conspicuous resulting in its detection. ${ }^{20,21,35}$ In this current study, if the magnetic field strength and voxel size were the only parameters that differed between the images, the mean SNR of the $4 \mathrm{~T}$ images would be expected to be 0.59 times as great as $1.5 \mathrm{~T}$. However, different pulse sequences and acquisition parameters such as repetition time, echo time, and receiver gain also differed between the two sets of images. The SNR of white matter, gray matter, CSF, and lesions were measured in order to determine if a higher signal contributed to the lesion volume and detection. When the ratios of $4 \mathrm{~T} \mathrm{SNR}$ to $1.5 \mathrm{~T}$ SNR from white matter, gray matter, CSF, and lesion on both the T2W and T1W images were averaged, the mean $4 \mathrm{~T}$ image SNR was found to be 0.69 times that of the $1.5 \mathrm{~T}$ image SNR indicating the use of different imaging hardware and pulse sequences had only a minor impact on mean image SNR. As expected, the 1.5 T T1W and T2W images had increased SNRs in more than one tissue type compared to the $4 \mathrm{~T}$ images. The signal intensity differences between the different tissues, expressed as CNRs, indicated the difference between white matter-lesion and gray matter-lesion were both higher and the difference between CSF-lesion was lower on the $\mathrm{T} 1 \mathrm{~W}$ images acquired at $4 \mathrm{~T}$. Since MS brain lesions are found within the white matter and typically have a periventricular or juxtacortical location, the increased CNR between gray matter-lesion would not expect to have a substantial outcome on the identification of lesions. The increased contrast between the white matter and lesions may have attributed to the detection of some lesions. However, if individual image slices from either $1.5 \mathrm{~T}$ or $4 \mathrm{~T}$ were viewed, it was difficult to identify which images were acquired at which field strength. The measurable differences in SNR and CNR did not produce a discernable qualitative difference. It is unlikely these factors had a major influence in lesion volume or detection in this study. Therefore, the increase in $4 \mathrm{~T}$ lesion load can be primarily attributed to the increased resolution of the $4 \mathrm{~T}$ images.

Image analysis methods are time consuming and prone to operator-induced errors as ambiguities often arise in identifying lesions and evaluating their size and extent. ${ }^{36-37}$ These difficulties arise from the fact that MS lesions are inherently fuzzy with "soft" rather than "hard" boundaries and small in size. A previous comparison of techniques found the semi-automated local thresholding techniques to be more reliable resulting in an intraobserver lesion load variability of $6 \%$ compared to $12-33 \%$ variability for the manual outlining technique. ${ }^{36}$ Although the intraobserver variability in lesion volume estimates is relatively low when a semi-automated segmentation tool such as Segtool is used, ${ }^{10}$ the degree of vacillation will depend on operator experience and characteristics of the image sets under analysis. Since all images in this study were analyzed using Segtool and reviewed by a single operator over a relatively short period of time, intraobserver variability was kept to a minimum (less than 6\%).

High-resolution MR imaging of MS subjects at $4 \mathrm{~T}$ results in dramatically improved lesion detection, which may have important implications for the study of MS and the design and monitoring of treatment trials. The increase in intrinsic SNR afforded by the use of a $4 \mathrm{~T}$ magnetic field permits the acquisition of images with increased resolution in times comparable to those used in current clinical settings at $1.5 \mathrm{~T}$. This improvement resolution resulted in a large increase in both the number and volume of MR-visible lesions, with a subsequent increase in total lesion load detected. In the current study, the use of $0.8 \mathrm{~mm}^{3}$ voxels at $4 \mathrm{~T}$, as compared to voxel volumes ranging from $5.3 \mathrm{~mm}^{3}$ at $1.5 \mathrm{~T}$, resulted in a $46 \%$ increase in the total number of lesions detected, a $60 \%$ increase in the mean lesion volume measured, and a $51 \%$ increase in total lesion load. The detection of large numbers of these small lesions, which in the current study represented $47 \%$ of all the lesions identified at $4 \mathrm{~T}$ (but only accounted for $4 \%$ of the total lesion volume), may also help to explain the discrepancies observed in studies of NAWM and the poor correlation that has been found between lesion load and clinical disability to date. The lesion load within individual subjects depends on the number, size distribution and location of lesions, the decrease in partial volume effects that accompanies the use of high-resolution images should reduce the variations in lesion load estimates. Thus, high-resolution $4 \mathrm{~T}$ imaging has the potential to substantially increase the accuracy of large-scale multicenter clinical trials and serial studies of MS.

\section{ACKNOWLEDGEMENTS}

Funding for this work was provided by the Multiple Sclerosis Society of Canada.

\section{REFERENCES}

1. Pretorius PM, Quaghebeur G. The role of MRI in the diagnosis of MS. Clin Radiol 2003; 58: 434-448.

2. Noseworthy JH, Lucchinetti C, Rodriguez M, Weinshenker BG. Multiple sclerosis. N Engl J Med 2000; 343: 938-952.

3. Weiner HL. A 21 point unifying hypothesis on the etiology and treatment of multiple sclerosis. Can J Neurol Sci 1998; 25: 93101.

4. Miller DH, Albert PS, Barkhof F, et al. Guidelines for the use of magnetic resonance techniques in monitoring the treatment of multiple sclerosis. Ann Neurol 1996; 39: 6-16.

5. Gareau PJ, Rutt BK, Bowen CV, Karlik SJ, Mitchell JR. In vivo measurements of multi-component T2 relaxation behaviour in guinea pig brain. Magn Reson Imaging 1999; 17: 1319-1325.

6. Bagnato F, Jeffries N, Richert ND, et al. Evolution of T1 black holes in patients with multiple sclerosis imaged monthly for 4 years. Brain 2003; 126: 1782-1789.

7. Jack CR Jr, Berquist TH, Miller GM, et al. Field strength in neuroMR imaging: a comparison of $0.5 \mathrm{~T}$ and $1.5 \mathrm{~T}$. J Comput Assist Tomogr 1990; 14: 505-513.

8. Steinberg HV, Alarcon JJ, Bernadino ME. Focal hepatic lesions: comparative MR imaging at 0.5 and 1.5 T. Radiology 1990; 174 : 153-156.

9. Lee JH, Garwood M, Menon R, et al. High contrast and fast threedimensional magnetic resonance imaging at high fields. Magn Reson Med 1995; 34: 308-312.

10. Mitchell JR, Karlik SJ, Lee DH, Fenster A. Computer-assisted identification and quantification of multiple sclerosis lesions in MR imaging volumes in the brain. J Magn Reson Imaging 1994; 4: 197-208.

11. Caramia F, Pantano P, Di Legge S et al. A longitudinal study of MR diffusion changes in normal appearing white matter of patients with early multiple sclerosis. Magn Reson Imaging 2002; 20(5): 383-388. 
12. Whittall KP, MacKay AL, Li DK, et al. Normal-appearing white matter in multiple sclerosis has heterogeneous, diffusely prolonged T(2). Magn Reson Med 2002; 47(2): 403-408.

13. Allen IV, McQuaid S, Mirakhur M, Nevin G. Pathological abnormalities in the normal-appearing white matter in multiple sclerosis. Neurol Sci 2001; 22(2): 141-144.

14. Cook LL, Foster PJ, Mitchell JR, Karlik SJ. In vivo 4.0-T magnetic resonance investigation of spinal cord inflammation, demyelination, and axonal damage in chronic-progressive experimental allergic encephalomyelitis. J Magn Reson Imaging 2004; 20(4): 563-571.

15. 't Hart BA, Bauer J, Muller H-J, et al. Histopathological characterization of magnetic resonance imaging-detectable brain white matter lesions in a primate model of multiple sclerosis: a correlative study in marmoset (Callithrix juacchus). Am J Pathol 1998; 153: 649-663.

16. Filippi M, Horsfield MA, Campi A, et al. Resolution-dependent estimates of lesion volumes in magnetic resonance imaging studies of the brain in multiple sclerosis. Ann Neurol 1995; 38 : 749-754.

17. Stone LA, Albert PS, Smith ME, et al. Changes in the amount of diseased white matter over time in patients with relapsingremitting multiple sclerosis. Neurology 1995; 45: 1808-1814.

18. Filippi M, van Waesberghe JH, Horsfield MA, et al. Interscanner variation in brain MRI lesion load measurements in MS: implications for clinical trials. Neurology 1997; 49: 371-377.

19. Horsfield MA, Barker GJ, Barkhof F, et al. Guidelines for using quantitative magnetization transfer magnetic resonance imaging for monitoring treatment of multiple sclerosis. J Magn Reson Imaging 2003; 17: 389-397.

20. Filippi M, Yousry T, Horsfield MA, et al. A high-resolution threedimensional T1-weighted gradient echo sequence improves the detection of disease activity in multiple sclerosis. Ann Neurol 1996; 40: 901-907.

21. Filippi M, Yousry T, Baratti C, et al. Quantitative assessment of MRI lesion load in multiple sclerosis: a comparison of conventional spin-echo with fast fluid-attenuated inversion recovery. Brain 1996; 119: 1349-1355.

22. Rovaris M, Gawne-Cain ML, Wang L, Miller DH. A comparison of conventional and fast spin-echo sequences for the measurement of lesion load in multiple sclerosis using a semi-automated contour technique. Neuroradiology 1997; 39: 161-165.

23. Filippi M, Rocca MA, Horsfield MA, et al. Increased spatial resolution using a three-dimensional T1-weighted gradientecho MR sequence results in greater hypointense lesion volumes in multiple sclerosis. AJNR Am J Neuroradiol 1998; 19: 235-238.

24. Filippi M, Horsfield MA, Rovaris $M$, et al. Intraobserver and interobserver variability in schemes for estimating volume of brain lesions on MR images in multiple sclerosis. AJNR Am J Neuroradiol 1998; 19: 239-244.

25. Grimaud J, Lai M, Thorpe J, et al. Quantification of MRI lesion load in multiple sclerosis: a comparison of three computer-assisted techniques. Magn Reson Imaging 1996; 14: 495-505.

26. Rovaris M, Rocca MA, Yousry I, et al. Lesion load quantification on fast-flair, rapid acquisition relaxation-enhanced, and gradient spin echo brain MRI scans from multiple sclerosis patients. Magn Reson Imaging 1999; 17: 1105-1110.

27. Firbank MJ, Coulthard A, Harrison RM, Williams ED. Partial volume effects in MRI studies of multiple sclerosis. Magn Reson Imaging 1999; 17: 593-607.

28. Wang L, Lai HM, Thompson AJ, Miller DH. Survey of the distribution of lesion size in multiple sclerosis: implication for the measurement of total lesion load. J Neurol Neurosurg Psychiatry 1997; 63: 452-455.

29. Molyneux PD, Tubridy N, Parker GJM, et al. The effect of section thickness on MR lesion detection and quantification in multiple sclerosis. AJNR Am J Neuroradiol 1998; 19: 1715-1720.

30. Filippi M, Gawne-Cain ML, Gasperini C, et al. Effect of training and different measurement strategies on the reproducibility of brain MRI lesion load measurements in multiple sclerosis. Neurology 1998; 50: 238-244.

31. Gawne-Cain ML, Webb S, Tofts P, Miller DH. Lesion volume measurement in multiple sclerosis: how important is accurate repositioning? J Magn Reson Imaging 1996; 6: 705-713.

32. Filippi M, Marciano N, Capra R, et al. The effect of imprecise repositioning on lesion volume measurement in patients with multiple sclerosis. Neurology 1997; 49: 274-276.

33. Filippi M, Paty DW, Kappos L, et al. Correlations between changes in disability and T2-weighted brain MRI activity in multiple sclerosis: a follow-up study. Neurology 1995; 45: 255-260.

34. Filippi M, Horsfield MA, Ader HJ, et al. Guidelines for using quantitative measures of brain magnetic resonance imaging abnormalities in monitoring the treatment of multiple sclerosis. Ann Neurol 1998; 43: 499-506.

35. Mastronardo G, Rocca MA, Rovaris M,..et al. A comparison of the sensitivity of monthly unenhanced and enhanced MRI techniques in detecting new multiple sclerosis lesions. Proceedings of the ISMRM, Sixth Scientific Meeting and Exhibition, Sydney, Australia, 1998: 1314.

36. Miller DH, Barkhof F, Berry I, et al. Magnetic resonance imaging in monitoring the treatment of multiple sclerosis: concerted action guidelines. J Neurol Neurosurg Psychiatry 1991; 54: 683-688.

37. Wicks DA, Tofts PS, Miller DH, et al. Volume measurement of multiple sclerosis lesions with magnetic resonance images. A preliminary study. Neuroradiology 1992; 34: 475-479. 